\title{
Typical Bronchial Carcinoid Metastasizing to the Brain: A Case Presentation
}

\author{
Simon B. Zeichner ${ }^{a} \quad$ Mike Cusnir $^{b} \quad$ Michael Francavilla $^{c}$ \\ Alicia Hirzel ${ }^{\text {d }}$ \\ Departments of ${ }^{\mathrm{a}}$ Internal Medicine, ${ }^{\mathrm{b}}$ Hematology and Oncology, ${ }^{\mathrm{C}}$ Radiology, \\ and ${ }^{\mathrm{d}}$ Pathology, Mount Sinai Medical Center, Miami Beach, Fla., USA
}

\section{Key Words}

Typical bronchial carcinoid · Brain metastasis - Lung cancer - Neuroendocrine tumors

\begin{abstract}
Introduction: Typical bronchial carcinoid tumors are known for their relatively indolent behavior. There are only four reported cases in the medical literature describing typical bronchial carcinoids metastasizing to the brain. Little is known about the pathogenesis and presentation of this disease due to the very small patient population.

Case Presentation: A 67-year-old Hispanic female presented to our hospital with a threeweek history of right arm numbness and poor coordination. Computed tomography (CT) with intravenous contrast of the brain and subsequent magnetic resonance imaging demonstrated multiple enhancing nodular densities throughout the brain. CT with intravenous contrast of the chest, abdomen, and pelvis revealed a left hilar mass and a medial left upper lobe mass. Histopathological findings were consistent with a neuroendocrine neoplasm of bronchial origin.

Conclusion: Although metastases to the central nervous system are very frequent with small cell carcinomas, their presence is very uncommon in well-differentiated neuroendocrine tumors such as the one we present here. This case raises questions about whether these tumors contain biomarkers that might predict a more aggressive behavior and if these patients might benefit from aggressive interventions similar to those taken in small cell carcinomas, such as prophylactic cranial radiation.
\end{abstract}

\section{Introduction}

Accounting for approximately 1-2\% of all lung malignancies in adults and roughly $20-30 \%$ of all carcinoid tumors, bronchial carcinoids are neuroendocrine tumors made up of peptide- and amine-producing cells originating from the embryologic neural crest [1-4]. Carcinoids originate most commonly from the gastrointestinal tract, but can also 
originate from the lung, thymus, and ovary. Bronchial carcinoids are broken down into typical and atypical tumors based on their pathologic tumor grade. Typical bronchial carcinoids are slow growing tumors that rarely metastasize, whereas atypical tumors metastasize early to the hilar or mediastinal nodes and are associated with a higher recurrence rate $[5,6]$. The average age of adults diagnosed with typical and atypical bronchial carcinoid tumors is 45 and 55 years, respectively [7-9]. Typical and atypical bronchial carcinoids have five-year survival rates ranging from 87-100 to 30-95\%, respectively [7, 10-24]. Bronchial carcinoids occur in $0.2-2$ per 100,000 individuals per year, with a higher incidence among women and Caucasians $[1-3,25,26]$. A major risk factor for tumor development is smoking, which accounts for up to half of all bronchial carcinoids [27-31] and an even greater percentage of atypical carcinoids [5, 30]. Patients with the autosomal dominant syndrome of multiple endocrine neoplasia type 1 (MEN1) are also at increased risk for bronchial carcinoid tumor development [27-31].

We report a case of a patient who presented with a typical carcinoid that metastasized to her brain.

\section{Case Presentation}

A 67-year-old Hispanic female presented to the emergency department complaining of a 3-week history of right arm numbness and poor coordination, during which eating, putting on makeup, and combing her hair had become increasingly difficult. Her past medical history was significant for wellcontrolled essential hypertension and recently diagnosed Behçet's syndrome. She smoked one pack a day for 37 years, quitting 15 years prior to the onset of symptoms. On admission, the patient was afebrile with stable vital signs. Physical examination revealed right hand paresis and abnormal cerebellar function, as seen with the finger-to-nose test. All laboratory results were within normal limits. Computed tomography (CT) with intravenous contrast of the brain and subsequent magnetic resonance imaging demonstrated multiple enhancing nodular densities throughout the brain, measuring up to $1.3 \mathrm{~cm}$ in maximum diameter (fig. 1). CT with intravenous contrast of the chest, abdomen, and pelvis revealed a $2.5 \times 2.7 \times 3.5-\mathrm{cm}^{3}$ left hilar mass encasing the left upper lobe apical segmental artery (fig. 2) and a $2.1 \times 2.1 \times 2.7-\mathrm{cm}^{3}$ medial left upper lobe mass abutting the anterior mediastinum. Bronchoscopic evaluation confirmed the findings of imaging studies and endobronchial

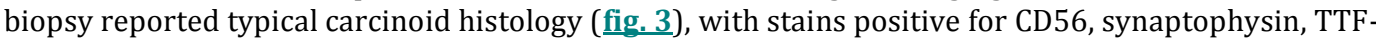
1, and napsin, and negative for p63, CK5, and chromogranin. Ki-67 was reported at approximately $50 \%$. Positron emission tomography-CT of the chest (fig. 4) and somatostatin receptor scintigraphy (fig. 5) confirmed the presence of hypermetabolic lung masses. A CT-guided percutaneous lung biopsy was performed on the hilar site to confirm the diagnosis given the rarity of central nervous system metastasis with this histology. This report, in addition to a report from a second opinion tissue sample referral center, concurred with the diagnosis. The patient was placed on steroid taper and her metastatic brain lesions were treated with stereotactic radiosurgery ( $16 \mathrm{~Gy}$ at $60 \%$ isodense) with complete improvement of neurologic symptoms. Surgical evaluation deemed the patient unresectable and plans were made to start concurrent chemotherapy and radiation.

Written informed consent was obtained from the patient for publication of this paper and accompanying images. A copy of the written consent form is available for review by the editor-in-chief of this journal.

\section{Discussion}

There are only four reported cases in the medical literature describing typical bronchial carcinoids metastasizing to the brain. The patients were reported in Japan, Israel, and Germany, and their ages ranged from 45 to 76 years [32-35]. 
Neuroendocrine tumors of the lung exist as a continuum from well-differentiated typical carcinoids to atypical carcinoids to extremely poorly differentiated small cell carcinomas. According to the $2004 \mathrm{WHO}$ criteria for the diagnosis of neuroendocrine tumors, there are specific pathological criteria that need to be met when describing each subset of tumor [36] (table 1). Although metastasis of small cell carcinomas has been well described, little is known about the pathogenesis and presentation of typical bronchial carcinoid metastasis due to the very small patient population. In addition to exploring the tumor's genetics and clinical tendencies, we must also understand the treatment modalities for this malignancy in order to ultimately improve patient survival.

Researchers have suggested several mechanisms to explain bronchial carcinoids' ability to metastasize, including dendritic cell apoptosis [36], deletions of 11q [37] and 4q25 [38], DNA methylation [39], and aneuploidy DNA content [40]. Other signals or genes that have been implicated include cell cycle inhibitor RB1 [41], drs tumor suppressor gene [42], phospholipase C beta 3 [43], and apoptosis signal caspase-8 [44]. Markers for malignant bronchial carcinoid tumor transformation include gastrinreleasing peptide [45], Bcl-2 [45], p53 [45], POU factor Brn3adel [46], and tyrosine kinase receptors c-kit, PDGFR alpha/beta, and EGFR [46, 47]. Additionally, CD44, nm23, and Ki-67 have all been shown to have prognostic significance for this tumor [46, 47].

Although the most common metastatic site of all carcinoid tumors is the liver, extrathoracic metastatic disease with bronchial carcinoid tumors is very rare, with one study citing a rate of $5 \%$ in a sample of 525 patients [1]. Most patients with bronchial carcinoids are asymptomatic and their diagnosis is often delayed considerably. Symptomatic patients can have hemoptysis from tumor hyper-vascularity or cough with recurrent pneumonia due to proximal airway obstruction. About three-fourths of bronchial carcinoids are centrally located and have a pink to red vascular mass appearance with intact bronchial epithelium.

Bronchial carcinoids, in addition to Merkel cell carcinomas, pheochromocytomas, medullary thyroid carcinomas, and pancreatic neuroendocrine tumors, arise from neuroendocrine cells and have the capacity to secrete biologically active neuroamines and neuropeptides. Despite the fact that less than $5 \%$ of patients exhibit hormonally related symptoms, typical and atypical bronchial carcinoids have the potential to cause carcinoid syndrome and Cushing's syndrome through ectopic production of serotonin [18] and adrenocorticotropic hormone [48-51], respectively. Approximately $80 \%$ of typical bronchial carcinoids and $60 \%$ of atypical tumors express somatostatin receptors and can be imaged with radiolabeled octreotide [11, 52-55]. Although this scan can image the entire body and identify metastatic disease outside the lung very easily, it has a very low specificity for disease detection $[55,56]$. Currently, there are no screening guidelines for bronchial carcinoid tumors and their presence can only be identified and confirmed through the use of radiographic studies and follow-up biopsy with immunohistological staining of the secreted products synaptophysin, neuronspecific enolase, and chromogranin [22]. In terms of treatment modalities, surgical resection with lymph node dissection offers the only chance of a cure from these tumors. Consensus guidelines from the National Comprehensive Cancer Network suggest the use of chemotherapy and radiation for resected stage II or III atypical carcinoids, but not for typical carcinoids [57]. Although randomized trials have revealed only minimal activity, metastatic bronchial carcinoid patients are often 
treated with small cell carcinoma-related regimens including prophylactic cranial radiation with cisplatin plus etoposide with or without paclitaxel or single agent temozolomide [58].

\section{Conclusion}

Although metastases to the central nervous system are very frequent with small cell carcinomas, their presence is very uncommon in well-differentiated neuroendocrine tumors such as the one we present here. This case raises questions about whether these tumors contain biomarkers that might predict a more aggressive behavior and if these patients might benefit from aggressive interventions similar to those taken in small cell carcinomas, such as prophylactic cranial radiation. Additionally, more data will need to be collected on metastatic typical bronchial carcinoid patients in order to better characterize the optimal radiographic and laboratory screening tests and the subsequent treatment modalities that will result in the best overall outcomes.

\section{Disclosure Statement}

The authors declare that they have no competing interests. No contributions were made nor was any funding provided towards this case presentation.

Table 1. WHO criteria for the pathologic diagnosis of neuroendocrine tumors, updated 2004

\begin{tabular}{|c|c|}
\hline Typical carcinoid & $\begin{array}{l}\text { Carcinoid morphology and }<2 \text { mitoses } / 2 \mathrm{~mm}^{2} \text { (10 HPFs), lacking necrosis and } \\
>0.5 \mathrm{~cm}\end{array}$ \\
\hline Atypical carcinoid & $\begin{array}{l}\text { Carcinoid morphology with } 2-10 \text { mitoses } / 2 \mathrm{~mm}^{2} \text { (10 HPFs) or necrosis (often } \\
\text { punctuate) }\end{array}$ \\
\hline $\begin{array}{l}\text { Large cell } \\
\text { neuroendocrine } \\
\text { carcinoma }\end{array}$ & $\begin{array}{l}\text { Neuroendocrine morphology (organoid nesting palisading rosettes, trabeculae) } \\
\text { High mitotic rate }>10 / 2 \mathrm{~mm}^{2} \text { (10 HPFs), median of } 70 / 2 \mathrm{~mm}^{2} \\
\text { Necrosis (often large zones) } \\
\text { Cytologic features of an NSCLC: large cell size, low nuclear to cytoplasmic ratio, } \\
\text { vesicular or fine chromatin, and/or frequent nucleoli; some tumors have fine } \\
\text { nuclear chromatin and lack nucleoli but qualify as NSCLC because of large cell size } \\
\text { and abundant cytoplasm } \\
\text { Positive immunohistochemical staining for one or more NE markers (other than } \\
\text { neuron-specific enolase) and/or NE granules by electron microscopy }\end{array}$ \\
\hline $\begin{array}{l}\text { Small cell } \\
\text { neuroendocrine } \\
\text { carcinoma }\end{array}$ & $\begin{array}{l}\text { Small size (generally less than the diameter of three resting lymphocytes) } \\
\text { Scant cytoplasm } \\
\text { Nuclei: finely granular nuclear chromatin, absent or faint nucleoli } \\
\text { High mitotic rate: }>11 \text { mitoses } / 2 \mathrm{~mm}^{2}(10 \mathrm{HPFs}) \text {, median of } 80 / 2 \mathrm{~mm}^{2}(10 \mathrm{HPFs}) \\
\text { Frequent necrosis, often in large zones }\end{array}$ \\
\hline
\end{tabular}




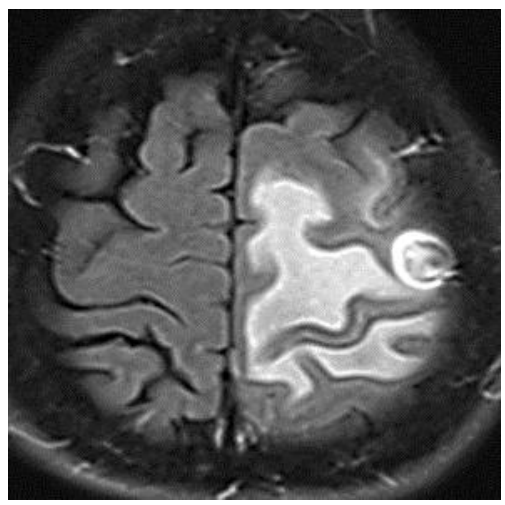

Fig. 1. MRI of the brain, T2 fluid-attenuated inversion recovery (FLAIR) post-contrast images, confirmed the presence of the lesions, measuring up to $1.3 \mathrm{~cm}$ in maximal diameter, with associated vasogenic edema in the left precentral gyrus, right occipital lobe, and bilateral frontal opercula.

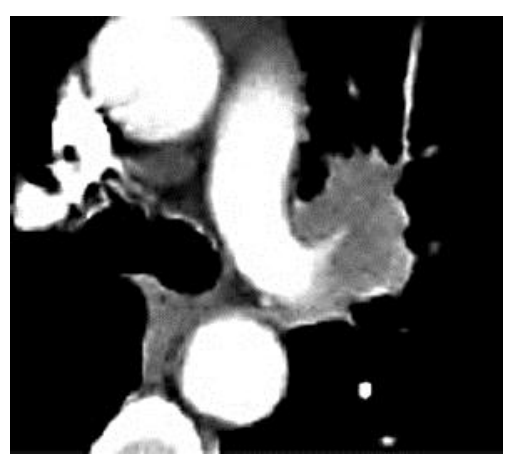

Fig. 2. CT with intravenous contrast of the chest, abdomen, and pelvis revealed a $3.5 \mathrm{~cm}$ left hilar mass encasing the left upper lobe apical segmental artery and $2.7 \mathrm{~cm}$ left upper lobe mass abutting the anterior mediastinum.

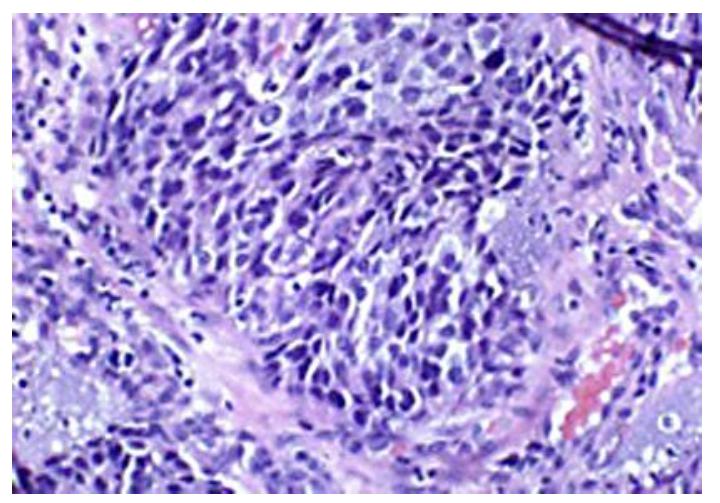

Fig. 3. Histopathological staining revealed a neuroendocrine neoplasm with stains positive for CD56, synaptophysin, TTF-1, and napsin and negative for p63 and CK5. Ki-67 was reported at approximately $50 \%$. 


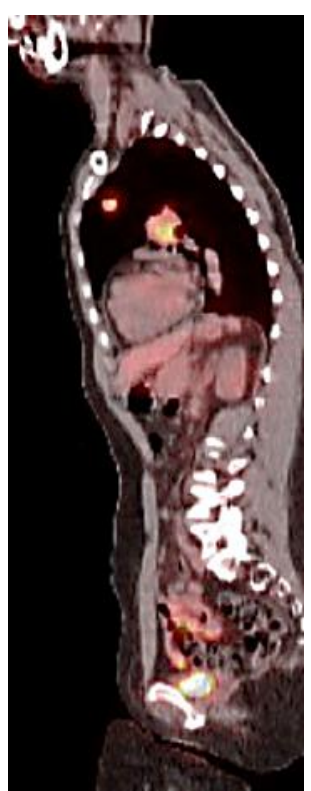

Fig. 4. Sagittal reconstruction shows hypermetabolic left perihilar and left upper lobe masses maximum standardized uptake value of 8.0.

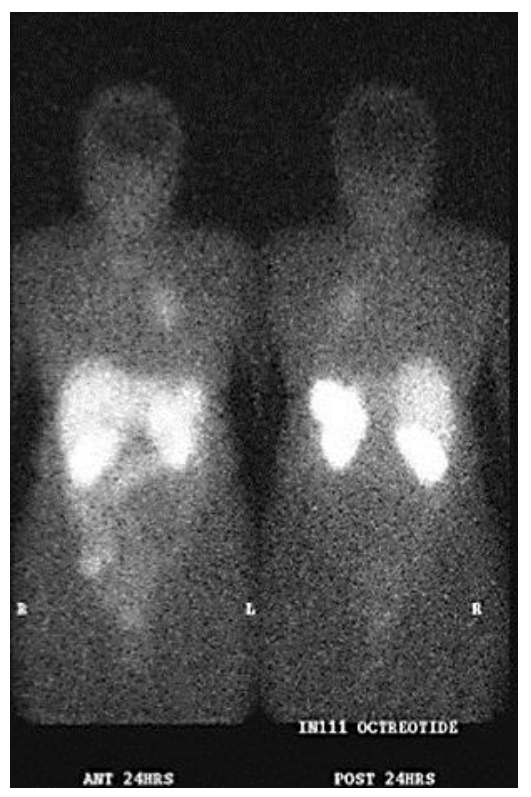

Fig. 5. Somatostatin receptor scintigraphy demonstrated moderate uptake of octreotide radiotracer within the left lung corresponding to the two left-sided masses seen on positron emission tomography-CT. 


\section{References}

$>1$ Quaedvlieg PF, Visser 0, Lamers CB, et al: Epidemiology and survival in patients with carcinoid disease in The Netherlands. An epidemiological study with 2,391 patients. Ann Oncol 2001;12:1295.

-2 Modlin IM, Lye KD, Kidd M: A 5-decade analysis of 13,715 carcinoid tumors. Cancer 2003;97:934.

-3 Hemminki K, Li X: Incidence trends and risk factors of carcinoid tumors: a nationwide epidemiologic study from Sweden. Cancer 2001;92:2204.

4 Hauso 0, Gustafsson BI, Kidd M, et al: Neuroendocrine tumor epidemiology: contrasting Norway and North America. Cancer 2008;113:2655

5 Matilla Gonzalez J, Garcia-Yuste M, Moreno-Mata N, et al: Typical and atypical carcinoid tumors (NEC grades 1 and 2): prognostic factors in metastases and local recurrence (abstract). Lung Cancer 2005;49(2 suppl):S60.

6 Kaplan B, Stevens CW, Allen P, et al: Outcomes and patterns of failure in bronchial carcinoid tumors. Int J Radiat Oncol Biol Phys 2003;55:125.

7 Zuetenhorst JM, Taal BG: Metastatic carcinoid tumors: a clinical review. Oncologist 2005;10:123.

8 Filosso PL, Donati G, Rena 0, Oliaro A: Acromegaly as manifestation of a bronchial carcinoid tumour. Asian Cardiovasc Thorac Ann 2003;11:189.

-9 Skuladottir H, Hirsch FR, Hansen HH, Olsen JH: Pulmonary neuroendocrine tumors: incidence and prognosis of histological subtypes. A population-based study in Denmark. Lung Cancer 2002;37:127.

10 Gatta G, Ciccolallo L, Kunkler I, et al: Survival from rare cancer in adults: a population-based study. Lancet Oncol 2006; 7:132.

-11 Gustafsson BI, Kidd M, Chan A, et al: Bronchopulmonary neuroendocrine tumors. Cancer 2008;113:5.

-12 Ferguson MK, Landreneau RJ, Hazelrigg SR, et al: Long-term outcome after resection for bronchial carcinoid tumors. Eur J Cardiothorac Surg 2000;18:156.

13 Thomas CF Jr, Tazelaar HD, Jett JR: Typical and atypical pulmonary carcinoids: outcome in patients presenting with regional lymph node involvement. Chest 2001;119:1143.

-14 Cardillo G, Sera F, Di Martino M, et al: Bronchial carcinoid tumors: nodal status and long-term survival after resection. Ann Thorac Surg 2004;77:1781.

15 Ducrocq X, Thomas P, Massard G, et al: Operative risk and prognostic factors of typical bronchial carcinoid tumors. Ann Thorac Surg 1998;65:1410.

16 Asamura H, Kameya T, Matsuno Y, et al: Neuroendocrine neoplasms of the lung: a prognostic spectrum J Clin Oncol 2006;24:70.

-17 Soga J, Yakuwa Y: Bronchopulmonary carcinoids: an analysis of 1,875 reported cases with special reference to a comparison between typical carcinoids and atypical varieties. Ann Thorac Cardiovasc Surg 1999;5:211.

18 Matilla Gonzalez J, Garcia-Yuste M, Moreno-Mata N, et al: Typical and atypical carcinoid tumors (NEC grades 1 and 2): Prognostic factors in metastases and local recurrence (abstract). Lung Cancer 2005;49(2 suppl):S60.

19 Harpole DH Jr, Feldman JM, Buchanan S, et al: Bronchial carcinoid tumors: a retrospective analysis of 126 patients. Ann Thorac Surg 1992;54:50.

20 Fiala P, Petrásková K, Cernohorský S, et al: Bronchial carcinoid tumors: long-term outcome after surgery Neoplasma 2003;50:60.

21 Gould PM, Bonner JA, Sawyer TE, et al: Bronchial carcinoid tumors: importance of prognostic factors that influence patterns of recurrence and overall survival. Radiology 1998;208:181.

22 Filosso PL, Rena O, Donati G, et al: Bronchial carcinoid tumors: surgical management and long-term outcome. J Thorac Cardiovasc Surg 2002;123:303.

-23 García-Yuste M, Matilla JM, Alvarez-Gago T, et al: Prognostic factors in neuroendocrine lung tumors: a Spanish multicenter study. Spanish Multicenter Study of Neuroendocrine Tumors of the Lung of the Spanish Society of Pneumonology and Thoracic Surgery (EMETNE-SEPAR). Ann Thorac Surg 2000;70:258.

24 Rea F, Rizzardi G, Zuin A, et al: Outcome and surgical strategy in bronchial carcinoid tumors: single institution experience with 252 patients. Eur J Cardiothorac Surg 2007;31:186.

25 Fink G, Krelbaum T, Yellin A, et al: Pulmonary carcinoid: presentation, diagnosis, and outcome in 142 cases in Israel and review of 640 cases from the literature. Chest 2001;119:1647. 
26 Yao JC, Hassan M, Phan A, et al: One hundred years after 'carcinoid': epidemiology of and prognostic factors for neuroendocrine tumors in 35,825 cases in the United States. J Clin Oncol 2008;26:3063.

27 Beasley MB, Thunnissen FB, Brambilla E, et al: Pulmonary atypical carcinoid: predictors of survival in 106 cases. Hum Pathol 2000;31:1255.

28 Erasmus JJ, McAdams HP, Patz EF Jr, et al: Evaluation of primary pulmonary carcinoid tumors using FDG PET. AJR Am J Roentgenol 1998;170:1369.

29 Kayser K, Kayser C, Rahn W, et al: Carcinoid tumors of the lung: immuno- and ligandohistochemistry, analysis of integrated optical density, syntactic structure analysis, clinical data, and prognosis of patients treated surgically. J Surg Oncol 1996;63:99.

-30 Froudarakis M, Fournel P, Burgard G, et al: Bronchial carcinoids. A review of 22 cases. Oncology 1996;53:153.

31 Brokx HA, Risse EK, Paul MA, et al: Initial bronchoscopic treatment for patients with intraluminal bronchial carcinoids. J Thorac Cardiovasc Surg 2007;133:973.

32 Takano S, Saitoh M, Miyasaka Y, et al: Bronchial carcinoid tumor with multiple brain metastasis. No Shinkei Geka 1994;22:343-348.

33 Ohnsmann A, Sachsennheimer W: Intracerebral metastasis of a bronchial carcinoid tumor. Neurochirurgia 1992;35:160-162.

34 Kon T, Hara N, Su M, et al: Multiple brain metastasis of bronchial atypical carcinoid: unusual MR imaging, case report. No Shinkei Geka 1997;25:815-818.

35 Shimon I, Hadani M, Nass D, et al: Malignant bronchial carcinoid tumor metastatic to the pituitary in a thyroid carcinoma patient: successful treatment with surgery, radiotherapy, and somatostatin analog. Pituitary 2004; 7:51-57.

36 Travis WD: The concept of pulmonary neuroendocrine tumors; in Travis WD, Brambilla E, MullerHermelink HK, Harris CC (eds): Pathology and Genetics: Tumors of the Lung, Pleura, Thymus, and Heart. Lyon, IARC Press, 2004, p 19.

-37 Katsenelson NS, Shurin GV, Bykovskaia SN, et al: Human small cell lung carcinoma and carcinoid tumor regulate dendritic cell maturation and function. Mod Pathol 2001;14:40-45.

-38 Zhao J, de Krijger RR, Meier D, et al: Genomic alterations in well-differentiated gastrointestinal and bronchial neuroendocrine tumors (carcinoids): marked differences indicating diversity in molecular pathogenesis. Am J Pathol 2000;157:1431-1438.

-39 Johansson M, Heim S, Mandahl N, et al: Cytogenetic analysis of six bronchial carcinoids. Cancer Genet Cytogenet 1993;66:33-38.

40 Toyooka S, Toyooka KO, Maruyama R, et al: DNA methylation profiles of lung tumors. Mol Cancer Ther 2001;1:61-67.

-41 Voortman J, Lee JH, Killian JK, et al: Array comparative genomic hybridization-based characterization of genetic alterations in pulmonary neuroendocrine tumors. Proc Natl Acad Sci 2000;107:13040-13045.

-42 Shimakage M, Kodama K, Kawahara K, et al: Downregulation of drs tumor suppressor gene in highly malignant human pulmonary neuroendocrine tumors. Oncol Rep 2009;21:1367-1372.

-43 el-Naggar AK, Ballance W, Karim FW, et al: Typical and atypical bronchopulmonary carcinoids. A clinicopathologic and flow cytometric study. Am J Clin Pathol 1991;95:828-834.

-44 Stålberg P, Granberg D, Carling T, et al: In situ RNA-RNA hybridization of phospholipase C beta 3 shows lack of expression in neuroendocrine tumors. Anticancer Res 2003;23(3B):2227-2232.

45 Ariyoshi Y, Takahashi T, Sugio K, et al: Differential inactivation of caspase-8 in lung cancers. Cancer Biol Ther 2002;1:65-69.

46 Shivapurkar N, Toyooka S, Eby MT, et al: Prognostic markers in patients with typical bronchial carcinoid tumors. J Clin Endocrinol Metab 2000;85:3425-3430.

-47 Leblond-Francillard M, Picon A, Bertagna X, et al: High expression of the POU factor Brn3a in aggressive neuroendocrine tumors. J Clin Endocrinol Metab 1997;82:89-94.

48 Granberg D, Wilander E, Oberg K: Expression of tyrosine kinase receptors in lung carcinoids. Tumour Biol 2006;27:153-157.

-49 Limper AH, Carpenter PC, Scheithauer B, Staats BA: The Cushing syndrome induced by bronchial carcinoid tumors. Ann Intern Med 1992;117:209.

50 Jones JE, Shane SR, Gilbert E, Flink EB: Cushing's syndrome induced by the ectopic production of ACTH by a bronchial carcinoid. J Clin Endocrinol Metab 1969;29:1.

-51 DeStephano DB, Lloyd RV, Schteingart DE: Cushing's syndrome produced by a bronchial carcinoid tumor. Hum Pathol 1984;15:890. 
52 Scanagatta P, Montresor E, Pergher S, et al: Cushing's syndrome induced by bronchopulmonary carcinoid tumors: a review of 98 cases and our experience of two cases. Chir Ital 2004;56:63.

53 Granberg D, Sundin A, Janson ET, et al: Octreoscan in patients with bronchial carcinoid tumours. Clin Endocrinol 2003;59:793.

54 Reubi JC, Kvols LK, Waser B, et al: Detection of somatostatin receptors in surgical and percutaneous needle biopsy samples of carcinoids and islet cell carcinomas. Cancer Res 1990;50:5969.

55 Weiss M, Yellin A, Husza'r M, et al: Localization of adrenocorticotropic hormone-secreting bronchial carcinoid tumor by somatostatin-receptor scintigraphy. Ann Intern Med 1994;121:198.

56 Yellin A, Zwas ST, Rozenman J, et al: Experience with somatostatin receptor scintigraphy in the management of pulmonary carcinoid tumors. Isr Med Assoc J 2005;7:712

57 National Comprehensive Cancer Network (NCCN) guidelines. Available at: www.nccn.org (accessed on August 22, 2011)

58 Ekeblad S, Sundin A, Janson ET, et al: Temozolomide as monotherapy is effective in treatment of advanced malignant neuroendocrine tumors. Clin Cancer Res 2007;13:2986-2991. 